
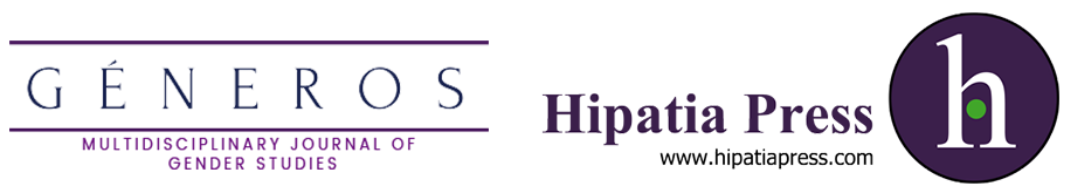

Instructions for authors, subscriptions and further details:

http://generos.hipatiapress.com

\title{
La Prostituta Como Víctima del Sistema Represivo Franquista. Un Análisis desde los Informes del Patronato De Protección a la Mujer
}

Carmen Guillén Lorente ${ }^{1}$

1) Universidad de Castilla la Mancha. España.

Date of publication: June 25th, 2021

Edition period: June 2021 - October 2021

To cite this article: Guillén-Lorente, C. (2021). La prostituta como víctima del sistema represivo franquista. un análisis desde los informes del patronato de protección a la mujer. Multidisciplinary Journal of Gender Studies, 10(2), 98120. doi: $10.17583 /$ generos.2021.5960

To link this article: http://dx.doi.org/10.17583/generos.2021.5960

PLEASE SCROLL DOWN FOR ARTICLE

The terms and conditions of use are related to the Open Journal System and

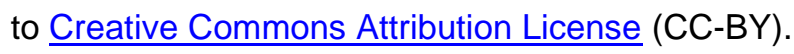




\section{The Prostitute as a Victim of the Franco Regime. An Analysis from the Reports of the Patronato de Protección a la Mujer}

Carmen Guillén Lorente

Universidad de Castilla la Mancha

\section{Abstract}

Prostitution analysis involves delving into a particularly controversial issue that can be undertaken from different complementary approaches. Its particular nature encompasses multiple daily facets, although we must point out that, in our case, the vision of this phenomenon is approached from the institutional perspective of the Women's Protection Board. This organism constituted during the Franco regime, the main oppressive organ for these women, and their seclusion in its multiple commercial centers available for a medical-psychiatric discourse that could subvert reality. In the end, as we shall see, what was veiled was the justification of a moral duality that allowed and punished its exercise in equal parts.

Keywords: prostitution, francoism, Patronato de Protección a la Mujer.

2021 Hipatia Press

ISSN: 2014-3613

doi: $10.17583 /$ generos.2021.5960 
GÉNEROS-Multidisciplinary Journal of Gender Studies Vol.10 No.2 June 2021 pp. 98-120

\section{La Prostituta como Víctima del Sistema Represivo Franquista. Un Análisis desde los Informes del Patronato de Protección a la Mujer}

Carmen Guillén Lorente

Universidad de Castilla la Mancha

\section{Resumen}

El análisis de la prostitución implica adentrarse en una cuestión especialmente controvertida que se puede emprender desde diferentes enfoques complementarios. Su naturaleza particular abarca múltiples facetas cotidianas aunque, en nuestro caso, la visión de ese fenómeno se aborda desde la óptica institucional del Patronato de Protección a la Mujer. Este organismo constituirá durante el franquismo el principal órgano opresivo para estas mujeres, y su reclusión en sus múltiples centros vendrá avalada por un discurso médico-psiquiátrico que intentó subvertir la realidad. A través del análisis de la abundante documentación generada por esta institución examinaremos la realidad social a la que tuvo que enfrentarse la prostituta durante los años de la dictadura franquista en los que se justificó una dualidad moral que permitía y castigaba su ejercicio a partes iguales.

Palabras clave: prostitución, franquismo, Patronato de Protección a la mujer 


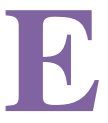

1 estudio de la represión franquista en todos sus ámbitos ha sido un tema recurrente en la historiografía de las últimas décadas. Ejecuciones, encarcelamientos, violencia física o exilio representan las formas más tangibles que practicó el nuevo Estado para perpetuarse en el poder; sin embargo, existió otro tipo de represión menos visible pero igualmente coercitiva que, si bien padeció el conjunto de la población, se reveló como un acoso específico y constante sobre el colectivo femenino. Nos referimos a la represión sexual llevada a cabo en aras de implantar un modelo de comportamiento moral determinado que desencadenó la aplicación de una estricta normativa en hábitos sociales y relación entre sexos. El control de este tipo de cuestiones resultaba muy complejo en la medida en que se trataba de temas vinculados directamente con la intimidad de la población; aun así, el franquismo supo desarrollar las estrategias pertinentes para imponer su criterio.

En este sentido el aparato represivo más efectivo y duradero sería el Patronato de Protección a la Mujer (Prieto, 2018; Guillén, 2018), institución creada en 1941 con el objetivo prioritario de redimir a la mujer caída y ayudar a la que estaba en peligro de caer ${ }^{1}$. En un sentido más amplio se podría decir que su función general estuvo ligada a la difusión de una normativa de conducta donde prevalecían la decencia, el recato o la castidad, mientras que su función más específica se centró en la redención de las prostitutas. Para implementar esa labor, el patronato desarrolló un estudiado sistema de vigilancia y reclusión cuya finalidad era liberar a la mujer de todas aquellas prácticas sociales que entraban en conflicto con las austeras reglas del régimen.

Además de las mencionadas funciones preventivo-redentoras, el patronato se encargaría también de realizar periódicamente un conjunto de estadísticas e informes que evaluaban la moralidad pública y que serán, a la postre, la base archivística del presente estudio. En estos informes o memorias ${ }^{2}$ se muestran todas las aristas de la cuestión moral que, en términos franquistas, comprenden elementos muy heterogéneos como el ambiente en bailes, cines y playas, la homosexualidad, el uso de estupefacientes, la prostitución, los abortos y la natalidad; temas de los que se ocupó la institución hasta su final definitivo, en plena década de los ochenta ${ }^{3}$. De todos ellos, la prostitución constituirá el asunto central pues representó desde muy temprano la 


\section{Guillén Llorente- La Prostituta Como Víctima del Sistema Represivo Franquista}

problemática a erradicar, de tal forma que este fenómeno constituye el argumento principal de la mayor parte de las memorias, donde se examinaron las causas, orígenes y, sobre todo, las posibles soluciones.

La historia de la prostitución en la España contemporánea, constituye hoy en día uno de los terrenos más fértiles y menos explorados de la historiografía española. Si bien es cierto que en los últimos años han sido varias las publicaciones que han dado luz a una parte hasta ahora oculta de nuestro pasado (Escobedo, 2019), el camino que queda por recorrer presenta aún unas perspectivas de investigación abundantes. De hecho, en el marco del nuevo Estado, la prostitución ofrece una interesante perspectiva analítica, pues su estudio permite encuadrar al fenómeno dentro de una sociedad generadora de desigualdades y evidencia más que cualquier otro aspecto la doble moral del régimen.

\section{La prostitución desde la religión y la psicopatología de la época: justificación y criminalización del fenómeno}

Durante el franquismo se diferencian claramente dos etapas legales en materia de prostitución: la primera reglamentarista, como reacción al sistema planteado por los republicanos (Rivas, 2013); y la segunda abolicionista ${ }^{4}$ aunque de corte claramente prohibicionista ${ }^{5}$, como consecuencia de la presión de ciertos sectores y, principalmente, por la adhesión de España a la Organización de las Naciones Unidas (Guereña, 2012). En este contexto el ejercicio de la prostitución planteó, desde el inicio del régimen, un reto para el nuevo Estado dado que su permisividad legal suponía atentar contra sus propias bases morales. De hecho, la postura oficial acerca de la prostitución fue bastante ambigua pues, de un lado se reglamentó y de otro, su figura fue estigmatizada; y así toda la retórica ultraconservadora y católica que promulgaba una sexualidad ligada únicamente al matrimonio y a la procreación, convivió en abierta contradicción con la normativa franquista durante quince años. Para justificar esta actitud el régimen difundió un discurso articulado desde dos perspectivas, la médica y -paradójicamente- la religiosa.

La medicina se esforzó en buscar las causas clínicas que favorecían la práctica de la prostitución y para ello la psiquiatría franquista se puso al 
servicio de la condena moral y social de las prostitutas. Este colectivo fue asociado entonces a una patología concreta, como si ellas mimas fueran portadoras de una serie de lacras psicopatológicas que las impulsaban irremediablemente a una vida de marginalidad y lujuria. Esta teoría defendida por el franquismo venía avalada por una importante tradición psiquiátrica internacional que ya había dado importantes pasos en ese sentido. Desde finales del siglo XIX, las teorías positivistas que relacionaban criminalidad y prostitución habían tomado fuerza a partir la obra de Cesare Lombroso (1903), para quien la prostitución era el equivalente de la criminalidad en la mujer, la forma específica bajo la que se manifestaba su degeneración (Lombroso, 1903, p. 621).

En España, el principal referente a ese respecto lo encontramos en la figura de Antonio Vallejo Nájera, que supo promocionar una personal visión de la eugenesia al reconciliar las doctrinas alemanas de la higiene racial con los preceptos de la moral católica (Bandrés et al., 2014, p. 1670). Sus teorías defendían que la prostitución viene definida esencialmente por un factor congénito y, en menor medida, por factores circunstanciales:

Claro está que en la prostitución intervienen complejos factores ambientales, pero son muchas las personas colocadas en iguales circunstancias que no se entregan al comercio sexual mercenario. Ha podido observarse la escasa intervención que tienen la pobreza, el alcoholismo de los padres, los malos tratos de la madrastra, las seducciones, etc. en la prostitución. Más frecuentemente interviene el factor constitucional (Vallejo Nájera, 1937, p. 133).

Las condiciones de carestía y penuria no fueron consideradas determinantes, porque ello supondría reconocer la precaria situación económica del país y su nefasta política autárquica. Se prefería alegar que la prostitución no era una elección, sino más bien un hecho innato a ciertas mujeres que se veían atraídas por el sexo y el lujo. Su sexualidad se entendía como equivocada al compararse con el discurso oficial de normalidad sexual femenina, que partía de la premisa de la pasividad sexual de las mujeres, dando por hecho que sus instintos en este sentido eran prácticamente nulos ${ }^{6}$. Se asumía que ellas entendían la relación carnal como una obligatoriedad conyugal y su disfrute debía quedar supeditado siempre al del hombre. En el lado antagónico, la 


\title{
103 Guillén Llorente- La Prostituta Como Víctima del Sistema Represivo Franquista
}

prostituta manifestaba abierto interés por el sexo desde muy joven y era incapaz de controlar sus bajas pasiones:

\begin{abstract}
Caracteriza a la prostituta congénita, constitucional, la volubilidad, ligereza, holgazanería y frivolidad que exterioriza desde la infancia. Ya en la niñez corretea por los bosques acompañada de muchachos y plácela coloquios a solas. Manifiesta prematura tendencia a barzonear por las calles, ir al café, visitar almacenes, leer novelas, suscitar conversaciones atrevidas. Coquetea con todos y se burla de todos. Posiblemente, a los nueve o diez años conoce el secreto de la vida y ya ha aprovechado todas las ocasiones oportunas que se le han presentado para el goce sexual (Vallejo Nájera, 1937, p.135).
\end{abstract}

Los textos de éstos y otros autores ${ }^{7}$, caracterizaron a las prostitutas como afectas innatas de psicopatía sexual, deficiencia mental y amoralidad, consiguiendo, de este modo, la justificación idónea para su encierro (Bandrés et al., 2014, p. 1670). Así, esos discursos psiquiátricos pretendían demonizar a la prostituta atribuyéndole una serie de patologías reconocibles que demostraban su inferioridad física y mental. El razonamiento era sencillo: existía una determinada forma de entender la normalidad femenina basada en virtudes como la sumisión, la abnegación, la delicadeza o la pasividad. A este respecto, cualquier patrón antagónico era juzgado como anómalo o potencialmente peligroso, y esto era suficiente argumentación para internar a las jóvenes en los centros del patronato o en las cárceles previstas para ellas.

La pregunta que se plantea entonces es clara: si la prostituta se consideraba una enferma patológica y una criminal en potencia ¿cómo se justificó su reglamentación durante buena parte de la dictadura franquista? Con el inicio del nuevo Estado, el gobierno se apresuró a derogar todo el corpus legislativo republicano. Cualquier vestigio de este periodo fue eliminado y la prostitución no constituyó una excepción; de modo que, en un primer momento, la reglamentación se retomaba de forma más circunstancial que deliberada. Sin embargo, el régimen advertiría muy pronto que su ejercicio le permitía mantener, paradójicamente, la honestidad de la buena mujer. El discurso franquista había establecido una femineidad asexual -en el sentido de castración de la iniciativa y del placer- y una masculinidad hipersexualizada, en la que el hombre estaba plenamente legitimado para sentir deseo. Se produjo así, un acusado desequilibrio en torno a la sexualidad que sólo se 
consiguió nivelar a través de la figura de la prostituta, que adquirió entonces un papel de moderadora entre estas dos concepciones polarizadas de la sexualidad.

Como complemento al discurso médico-psiquiátrico el franquismo encontró en la religión la base teórica sobre la que acreditar el ejercicio de la prostitución. Se esgrimieron argumentos teológicos en favor de su reglamentación, basados principalmente en el pensamiento de San Agustín, para quien los prostíbulos hacían las veces de freno contra la corrupción de las costumbres y los desórdenes sexuales:

Qué cosa más sórdida, ni más indecorosa, ni más inmunda que las meretrices, los alcahuetes, ¿qué no se puede decir de toda esta peste de gente? Sin embargo, suprime en la sociedad las mujeres públicas y lo llenarás todo de vicios. Pon a éstas en el lugar de las mujeres honradas y lo deshonrarás todo con impureza y fealdad (Citado por el Patronato de Protección a la Mujer, 1943, p. 215).

El enfoque teológico moral de la prostitución se resolvía con esa categórica visión agustiniana, que tiempo después recogería también Santo Tomás. El planteamiento doctrinal del problema define a la prostituta como un mal social inevitable y, a la vez, necesario; inevitable porque se considera intrínseco a la propia condición humana $\mathrm{y}$, necesario, porque su permisión protege a la sociedad de males mayores y sirve de salvaguarda de ciertos valores como la castidad, la honra o la pureza. Parece entonces que de la propia inevitabilidad de la prostitución derivaba automáticamente su aceptabilidad. Esta circunstancia fue explicada a través del irreprimible impulso sexual masculino; reconocido éste, se entendía menos grave la relación carnal con una prostituta que con una mujer soltera o entre dos hombres. De este modo, la justificación estuvo basada en la salvaguarda de colectivos que socialmente resultaban prioritarios, como las mujeres buenas, la familia cristiana e, incluso, los hombres, a quienes se les protegía de la homosexualidad. La prostitución se entendía como un verdadero servicio social, y según esta teoría, el estereotipo de mujer ideal difícilmente podía sobrevivir sin la existencia de la prostituta; así, la máxima latina an ad vitanda majora mala permittendae sint meretrices -para evitar males mayores se permite la prostitución- sirvió durante muchos siglos de escudo doctrinal a los partidarios de la tolerancia. San Agustín adquirió el papel de autoridad moral al respecto 


\section{Guillén Llorente-La Prostituta Como Víctima del Sistema Represivo Franquista}

estableciendo una analogía entre la prostitución y las cloacas ${ }^{8}$, pues de la misma manera que estas últimas salvaguardaban la sanidad de la ciudad acogiendo la suciedad, las prostitutas salvaguardarían a la sociedad, al albergar la inmoralidad.

No obstante, según el patronato, la teoría agustiniana respecto a la prostitución no fue siempre plenamente aceptada, y muchos teóricos cuestionaron su validez ${ }^{9}$. El principal opositor al pensamiento agustiniano respecto a la prostitución fue Marcelino Zalba, reputado jesuita y moralista del momento que, con su obra, La prostitución ante la moral y el derecho (1942), tomó partido a favor del abolicionismo, desarmando la desgastada teoría del mal menor:

Aunque admitamos en algunos casos que pueda evitar otros excesos, ella cultiva y desarrolla el vicio, encanalla y destruye a miles y miles de hombres, degrada y envilece a las mujeres, seduce a los niños, es una amenaza a la honra y un peligro para la sociedad, bastante peor en sí mismo que el socialismo y el comunismo (Zalba, 1942, p. 31).

Para Zalba, la máxima agustiniana enturbió durante siglos el enfoque moral de la cuestión por falta de una adecuada crítica histórica. Ciertamente la ética cristiana había condenado siempre la prostitución como un hecho inmoral al implicar el acto sexual fuera de la relación conyugal; por la degradación de las personas que se prostituyen y porque tiene una estrecha relación con el adulterio, el uso de contraceptivos y la posibilidad del aborto (Ortega, 2002, p. 59). En su opinión “...el grado de cultura y civilización de los siglos V y XIII muy bien pudieron aconsejar esta actitud -se refiere a la reglamentación de la prostitución- que en el siglo XX estaría fuera de lugar" (Zalba, 1942, p.47).

Pese a todo, el nacionalcatolicismo supo justificar su postura ante un hecho que era la representación antagónica de todos los valores morales defendidos por el régimen. Según la visión oficial, la prostitución era aceptable como fenómeno colectivo, pero la prostituta como individuo era reprochable; de modo que la conceptualización de la prostituta basculaba desde un punto de vista individual, entre criminal y enferma mental, y desde el punto de vista social como un mal menor inevitable y, al mismo tiempo, condenable. Sólo en este marco conceptual se entiende la armónica convivencia entre permisividad y castigo al encarnar la prostituta la máxima expresión de la 
doble moral franquista quedando segregada de una sociedad que renegaba y amparaba su ejercicio a partes iguales.

\section{Establecimientos de reclusión y reforma: el papel del Patronato de Protección a la Mujer en la prostitución}

El régimen franquista instrumentalizó la prostitución mediante un particular discurso de aceptación y criminalización del fenómeno. Esta doble moral propició que el sistema reglamentarista transcurriera en paralelo a la creación de una serie de medidas y establecimientos de corte represivo para favorecer el control de estas mujeres. Lo cierto es que el crecimiento inusitado de la prostitución en los primeros años del régimen ponía en evidencia la precaria situación del país y suponía, además, un importante descontrol de las enfermedades venéreas ${ }^{10}$. El principal problema era que la prostitución no se circunscribía al interior de los prostíbulos, es más, existía una amplia variedad en las formas de actuación que puede resumirse en tres grandes categorías: la prostitución pública, ejercida a través de terceros - proxenetas- en establecimientos reglamentados; la prostitución privada, ejercida libremente por las profesionales del sexo pero sujetas a inspecciones sanitarias y policiales; y la prostitución clandestina, ejercida al margen de la ley (Patronato de Protección a la Mujer, 1942, p. 147). El aumento exponencial de este último tipo de prostitución, ligado al considerable incremento de enfermedades de transmisión sexual, favorecieron la creación de una serie de establecimientos de reclusión y reforma que les permitía promover un activo control sobre ellas. Una vez demonizada la prostituta por los especialistas en salud mental, el Estado tenía la potestad para ejercer su poder libremente y de forma indiscriminada (Bandrés et al., 2014, p. 1677). Según este razonamiento se daba por hecho que la prostituta era una víctima que necesitaba regeneración médica, pero sobre todo regeneración moral:

Si se quiere sacar a una prostituta de su esclavitud no hay que pensar, en general, en devolverla directamente a la vida social. Es una gran enferma física, psíquica y moral. Todo en ella se ha sacrificado y matado. Vive fuera de toda familia natural o adoptiva, fuera del orden social. Su incorporación a la sociedad sólo es posible a través de una casa de rehabilitación (Patronato de Protección a la Mujer, 1965, p. 43). 


\section{Guillén Llorente- La Prostituta Como Víctima del Sistema Represivo Franquista}

El objetivo siempre fue mantener unas zonas de la ciudad adaptadas para este tipo de actividad, alejadas de los centros y a modo de guetto $^{11}$, con el propósito de ocultar la realidad, más que de solucionar el problema de fondo. En consecuencia, ejercer la prostitución fuera de estos límites, de forma clandestina o evitando los controles sanitarios, suponía exponerse al arresto policial y al encierro penitenciario. El complicado entramado de instituciones represivas para prostitutas desarrollado durante el franquismo, heredó sus objetivos y formas de las detenciones en cárceles en las que eran muy conocidas las llamadas "quincenarias" ${ }^{2}$, prostitutas a las que se obligaba a una estancia de quince días en dependencias judiciales (Núñez, 2003, p. 2223). Sin embargo, dicho sistema se había revelado como ineficaz ante el aumento de este tipo de prostitución, la masificación de las cárceles propia de los años de posguerra y los continuos enfrentamientos entre presas comunes y políticas (Osborne, 2009, p. 55-77). Además de estos encierros penitenciarios, eran frecuentes también otras medidas que incluían multa, arresto gubernativo y rapado de pelo ${ }^{13}$. Pese a todo, la prostitución clandestina resultaba más atractiva, en cuanto a que eximía la retribución al proxeneta, evitaba los abusivos controles médicos ${ }^{14} \mathrm{y}$ podía ser ejercida por menores. No es de extrañar entonces que muchas jóvenes se decantaran por esta modalidad, que vivió un considerable repunte durante los primeros años de la posguerra.

En este contexto de aumento de la prostitución clandestina, el Estado franquista consideró oportuno crear una serie de centros penitenciarios específicos para las denominadas mujeres caídas cuyo decreto fundacional, promulgado en 1941, justificaba así su creación: “...por la inmoralidad que se padece en los momentos actuales, como consecuencia de la época de descristianización que imperó en España en los últimos años hasta el advenimiento del Glorioso Movimiento Nacional" ${ }^{15}$. La herencia republicana siempre era bien recibida como argumento para condenar comportamientos morales y, en justa correspondencia, las prostitutas fueron encerradas en nombre del "buen gobierno y las buenas formas". Una vez dentro, estas mujeres desviadas eran moralizadas por personal religioso, principalmente por monjas Adoratrices que ya contaban con una dilatada experiencia en este tipo de tareas asistenciales (De Cossío y Gómez Acebo, 1911, p. 61 y 62). La reeducación moral femenina representaba una parte indispensable del proceso penitenciario pues, como ya apuntó Mary Nash, el encierro carcelario de esas 
mujeres no hacía sino reforzar la ecuación "activistas-puta" al equiparar delincuencia con inmoralidad (Nash, 1997, p. 161).

Según el reglamento de 1948, estas cárceles se clasificaban en seis categorías: "Reformatorios de mujeres, Central Común, Hospital Penitenciario de Mujeres, Clínica Psiquiátrica, Sanatorio antituberculoso y Central de Multireincidentes". Todos ellos dependían del Ministerio de Justicia y Gobernación y quedaron bajo el mando de Máximo Cuervo, director general de prisiones y presidente del Patronato para la Redención de Penas por Trabajo, que resaltó la necesidad de crear estos centros específicos para prostitutas:

Cuando (...) me informaron del grandísimo número de mujeres de las dedicadas al comercio vil que ingresaban en las prisiones a cumplir quincenas por faltas relacionadas con su inmoral tráfico, me hicieron saber al mismo tiempo el peligro que para otras mujeres, en su mayor parte producto de la delincuencia roja, pero honradas en el orden sexual, suponía la convivencia con aquellas en un mismo establecimiento durante algunas semanas ${ }^{16}$.

Con todo, las propias autoridades reconocieron como ineficaces las medidas planteadas y el Estado se dispuso entonces a completar el dispositivo de control no sólo sobre la prostitución en sí misma, sino sobre la moralidad pública vista siempre desde la perspectiva de la desviación femenina. Dentro del contexto de intervencionismo las autoridades incorporaron, también en 1941, otros dos mecanismos de vigilancia y encierro para mujeres: los reformatorios del Patronato de Protección a la Mujer y la Obra de Redención de Mujeres Caídas (Núñez, 2003). Ambos nacieron en paralelo con el "objetivo de orientar con su experiencia y su estudio la política más conveniente en materia de prostitución” (Núñez, 2003, p. 41) aunque con ciertos matices diferenciadores. En principio, la Obra estuvo más enfocada a la reeducación moral y cura sanitaria de mujeres "extraviadas" mientras que el Patronato tuvo propósitos mucho más heterogéneos que iban desde la vigilancia moral hasta el control conductual en su más amplio sentido. Con todo, no hay duda que la prostitución fue desde su fundación el eje central de sus preocupaciones, tal y como lo atestiguan los primeros informes publicados: 


\section{Guillén Llorente- La Prostituta Como Víctima del Sistema Represivo Franquista}

Aunque la jurisdicción y, por ende, las atribuciones del Patronato de Protección a la Mujer son amplísimas en materia de moralidad, según dispone el Decreto de 6 de noviembre de 1941, el problema más arduo, agudo y complejo que tiene encomendado, como sucesor del antiguo Patronato Real para la Represión de la Trata de Blancas, es el de orientar con su experiencia y su estudio la política más conveniente en materia de prostitución (Patronato de Protección a la Mujer, 1942, p. 73).

Dentro de la misión tuitiva del patronato conviene distinguir dos facetas: la primera, jurídica, cuyo aspecto incluía una triple tarea: acordar el internamiento de la menor en un centro adecuado; promover ante la jurisdicción ordinaria la supresión de la patria potestad en los casos pertinentes; e investigar los hechos motivadores de la situación de prostitución o corrupción de la joven, con objeto de denunciarlos a la autoridad judicial para que procediera al encausamiento de los culpables (Patronato de Protección a la Mujer, 1942, p. 38). La segunda fue la función asistencial, realizada a través del internamiento en establecimientos adecuados, una vez efectuada la oportuna observación y clasificación de las jóvenes con el correspondiente estudio médico-social-cultural de cada una.

Aunque estas dos funciones son señaladas como prioritarias en los objetivos de la institución, no debemos olvidar que el elemento central de los centros fue su misión reeducadora, que quedó integrada por la formación espiritual, social y profesional. La educación espiritual constituía el pilar de carga de todo el proceso redentor, pues según su criterio, “...únicamente cuando la mujer cuenta con el suficiente desarrollo de sus resortes espirituales, está en condiciones de enfrentarse con los imponderables que le rodean" (Patronato de Protección a la Mujer, 1965, p. 38). De este modo, catequesis, largas horas de rezo, rosario y misa dominical se instauraron como parte imprescindible de la rutina diaria de los centros. La redención de la prostituta no se entendía sin una completa educación religiosa, y la salida de los centros dependía casi exclusivamente de su actitud en este sentido, en tanto que se consideraba la prostitución como un "asunto que requiere ante todo unos principios políticos cimentados en el dogma y en la moral cristiana (Patronato de Protección a la Mujer, 1942, p. 74)".

Este escenario de reclusión y reeducación de prostitutas clandestinas se mantuvo hasta 1956, cuando por virtud del Decreto Ley de 3 de marzo ${ }^{17}$, fue 
ordenada la clausura de las casas de tolerancia. Se encomendó entonces al patronato la tarea de acoger en sus establecimientos no sólo a las menores, sino también a todas aquellas mujeres caídas, mayores de edad, que voluntariamente desearan su readaptación a la vida social. Para ello, el patronato impulsó un tipo de local específico conocido popularmente como Villa Teresita que habían nacido en 1942 en Pamplona. Desde allí había ido creciendo hasta crear otros establecimientos también en Madrid, Barcelona, Granada y Godella con un considerable éxito; entre 1942 y 1973 más de 2.500 mujeres pasaron por algunas de las residencias de estas casas de acogida (Núñez, 2003, p. 47).

El objetivo de dichos centros fue obtener "muchachas sanas y equilibradas, purgadas de sus vicios" (Patronato de Protección a la Mujer, 1965, p. 44) a través del aprendizaje de un nuevo oficio, para cuyo fin se establecieron diversos talleres en cada una de las casas. Solían ser trabajos sencillos en los que no se precisaba instrucción académica, dándose por hecho que su capacidad intelectual era muy limitada y que tenían cierta preferencia por las labores rutinarias ${ }^{18}$. Así, en Pamplona se creó un taller de encuadernación, una peluquería en Granada, un taller de punto de Godella y diversos trabajos de artesanía que iban surgiendo en las distintas épocas y ciudades: muñequería, traslado a tul de blondas antiguas, corbatería o empalmado de punto (Patronato de Protección a la Mujer, 1965, p. 46).

Más allá de Villa Teresita, después de la reforma legal de 1956, el patronato mantuvo su misión correctivo-preventiva sobre las jóvenes que continuaron ejerciendo al margen de la ley. Y es que, la compleja realidad de la prostituta afectaba tanto a legales como a clandestinas; las primeras vivían supeditadas a una madame o a un proxeneta a los que debía de retribuir; las segundas, que trabajaban por libre, vivían bajo amenaza de reformatorio o cárcel, donde tampoco eran bien vistas por sus propias compañeras. El limbo legal en el que se desenvolvía el oficio propició que la vida de la prostituta se moviera siempre en un contexto de hipocresía moral y legal. En función de esta circunstancia, el Estado, amparado por los discursos médico-científicos de la época, supo crear un complejo aparato represivo capaz de controlar a aquellas mujeres que se atrevieron a ejercer fuera de los recintos y zonas habilitadas. El resultado fue la creación de varios dispositivos de control, reforma y encierro que pudieran gestionar la complejidad del problema. 


\section{Guillén Llorente-La Prostituta Como Víctima del Sistema Represivo Franquista}

\section{Evaluación de la prostitución a través de los informes del Patronato de Protección a la Mujer}

Además de la tarea reeducadora, otra de las funciones esenciales del patronato fue la elaboración de un discurso teórico-práctico sobre el estado de la prostitución nacional; en dicho alegato se abordarían tanto las causas y las consecuencias de este hecho, como las posibles soluciones. Los extensos informes redactados por la institución incorporaron ciertas informaciones de tipo numérico que nos ayudan a reconstruir el panorama prostitucional de los primeros años del franquismo. Los datos estadísticos se entremezclan con extensas disertaciones morales acerca de la cuestión, mostrando una visión heterogénea de la prostitución. La combinación de todos estos indicadores ofrece la posibilidad de estudiar el fenómeno a través de distintos enfoques analíticos al arrojar luz sobre una circunstancia que de otro modo resultaría difícilmente cuantificable. Los informes sobre moralidad pública que abordan el tema de la prostitución fueron redactados entre 1941 -reglamentación de la prostitución y primeras memorias oficiales- y 1952 -últimas memorias nacionales publicadas antes de la vuelta del abolicionismo- y varían mucho de unas memorias a otras, aunque mantienen el análisis desde una posición muy particular, expresada mediante una retórica condenatoria y peyorativa hacia este hecho:

El Estado español desciende a la triste realidad del problema de la prostitución proclamando los principios de que la lujuria es pecado, de que no puede moralmente permitir el escándalo público, el comercio carnal, ni consentir tampoco la esclavitud física y espiritual de unas mujeres al servicio de un perverso interés económico ajeno, si la represión es posible y no trae consigo mayores males (Patronato de Protección a la Mujer, 1943, p. 75).

Más allá de las consideraciones teóricas, el corpus de las memorias lo constituyen los informes elaborados a partir de las respuestas de las juntas provinciales a los completos cuestionarios enviados periódicamente desde la Junta Nacional ${ }^{19}$. Una de las cuestiones más preocupantes para la institución fue determinar las causas que impulsaban a las mujeres a ejercer esa actividad, entre las que sobresalía el afán de lujo y el vicio. En realidad, se aludía a 
constantes contradicciones, pues por una parte se defendía la naturaleza perversa de la prostituta asumiendo que su actividad era congénita, y por otra se mencionaban los elevados porcentajes de mujeres que ejercían por carencias económicas (Patronato de Protección a la Mujer, 1942, p. 83). Al fin y al cabo, la escasez de aquellos años, unida al abandono y orfandad al que se vieron sometidas muchas de ellas durante los años de la posguerra fueron indiscutiblemente los factores que propiciaron el aumento de las prostitutas.

Debido a esta escasez económica, el número de mujeres prostituidas se vio incrementado respecto al periodo republicano y sólo en los primeros meses de actuación del patronato se detuvieron por causas relacionadas con este hecho a casi 6.000 mujeres $^{20}$. Las cifras, teniendo en cuenta la moral imperante, eran alarmantes: sólo un año después de la reglamentación de la prostitución, el primer informe del Patronato de Protección a la Mujer estimó el número de prostitutas en 12.180 repartidas en 1.056 casas de tolerancia, con Barcelona (1.144 legales y 1.400 clandestinas), Valencia (1.050 legales y 700 clandestinas) y Málaga (850 legales y "muchas clandestinas") a la cabeza.

En términos generales, los informes de esta etapa inicial arrojan cifras más altas en las provincias de levante y sur que en las del centro y norte peninsular, más en las de litoral que las de tierra adentro, presentando así a la prostitución como un fenómeno eminentemente costero (Patronato de Protección a la Mujer, 1944, p. 234). El patronato insiste sobre todo en que la prostitución tuvo un desarrollo menor en las ciudades y regiones caracterizadas por "el mantenimiento de los principios tradicionales hispánicos, religiosos, morales y politicosociales", que en aquéllas donde fue más activa y notoria la difusión de doctrinas opuestas a estos principios (Patronato de Protección a la Mujer, 1944, p. 234). La interpretación particular de los redactores trató de vincular el mal con todo aquello relacionado con la II República y, en este sentido, la prostitución parece que tendría un peso destacado en las regiones más alejadas mentalmente de los valores tradicionales. Así, la zona castellanonavarra presentaba un escenario mucho más favorable que, por ejemplo, el levante y el sur, planteando de este modo una relación directamente causal entre republicanismo y prostitución.

En realidad, el fenómeno prostitucional se había extendido por todo el territorio nacional con independencia de la región, mientras que las cifras de cada demarcación atendían más a variables demográficas, que a pensamiento político. Al año siguiente, en 1944, las memorias reflejaban un incremento de 


\section{Guillén Llorente- La Prostituta Como Víctima del Sistema Represivo Franquista}

los lupanares de casi medio millar, sin incluir Madrid ni Barcelona. Se advertía además que los datos totales habrían de ser aumentados, al menos en un 25 por ciento, pues los informes contenían noticias relativas a las capitales y excluían las cifras de las localidades de cada provincia. Teniendo en cuenta esta medida y suponiendo además que la prostitución clandestina superaba en un ochenta por ciento a la legal (Zalba, 1942, p.7), podemos establecer una estimación aproximada de unas 32.300 prostitutas, repartidas por toda la geografía española ${ }^{21}$. Al final, resultó que la mojigata y recatada España de Franco se había convertido en realidad en un inmenso prostíbulo ${ }^{22}$. De hecho, el número de prostitutas se mantendría más o menos estable durante todo el periodo del que se tiene registro, variando muy poco respecto a la cifra de los años iniciales (Patronato de Protección a la Mujer, 1948, p. 55).

No obstante, hay que tener en cuenta que resulta extremadamente complejo apreciar el número real de mujeres que durante aquellos años se dedicaron al comercio carnal. Si comparamos las cifras arrojadas por el patronato con otras estimaciones publicadas, se comprueba de inmediato la falta de consenso. Por ejemplo, mientras que el patronato había calculado unas 12.000 prostitutas para 1941, las cifras publicadas por Rafael Torres hablan de unas 200.000 para el año 1940 (Torres, 1996, p. 119). Esta falta de consenso muestra la complejidad en el análisis de un fenómeno que tuvo en el disfraz su característica más notable, existiendo innumerables locales donde se ejercía sin control policial: bares, hoteles, cabarets, peluquerías, pensiones, etc. Esta circunstancia sería sin duda uno de los temas centrales de los informes y uno de los principales problemas a los que se enfrentó el patronato:

Pese a las medidas y vigilancia de la policía, existe un gran número, en su mayoría sirvientas y viudas jóvenes de la guerra que, unas por vicio y otras por no contar con otros ingresos, se dedican a la prostitución clandestina en sus propios domicilios o en casas de citas, pudiendo asegurarse que en donde menos se ejerce la prostitución es en las casas autorizadas (Patronato de Protección a la Mujer, 1943, p. 41).

En todas las memorias se señala un alarmante aumento de mujeres que ejercían de forma clandestina, sobre todo en las provincias donde el clima parecía favorecer la "precocidad femenina" (se citan aquí Valencia y Sevilla) y donde el "influjo desmoralizador de transeúntes extranjeros" propiciaba un 
número más elevado de este tipo de oferta (se refiere en este caso a Baleares y Canarias). De este modo, los inquisidores morales del patronato condenaban a todo lo ajeno al ser hispánico (Prieto, 2017, p. 3783) y la llegada del turismo a ciertas zonas del país se percibía como contaminante en términos morales. Evidentemente, el aumento de prostitución clandestina estuvo más vinculado a factores relacionados con la opresiva explotación de la que eran víctimas las mujeres en los lupanares. También era frecuente que en el colectivo de "clandestinas" se refugiaran las jóvenes menores de edad, a las que no se les permitía ejercer dentro de los prostíbulos. Asimismo, es preciso destacar que los datos a este respecto resultaban, en general, bastante sencillos de falsear y la suplantación de personalidad en las fichas de las prostitutas era, en palabras de la propia institución, "frecuentísima y nada difícil (Patronato de Protección a la Mujer, 1944, p. 237)", al usar las jóvenes los documentos de hermanas o amigas mayores de edad.

Sobre el tipo de clientela que frecuentaba estos establecimientos se tienen datos muy variados, que dependen principalmente del tipo de prostíbulo, aunque el retrato del cliente habitual solía asociarse con la marginalidad, el alcoholismo y con ciertos colectivos errantes - militares - o con hombres desvinculados del matrimonio - viudos o solteros- (Patronato de Protección a la Mujer, 1944, p. 236) La realidad distaba bastante de este retrato imaginario, pues durante el franquismo el prostíbulo se había consagrado como espacio de sociabilidad masculina (Guereña, 2003), al que solían acudir con relativa frecuencia colectivos de hombres muy diversos ${ }^{23}$. Como recuerda el profesor Guereña, más del sesenta por ciento de los primeros encuentros sexuales de los españoles durante el periodo franquista comenzaron con una prostituta, incluso cuando su actividad dejó de estar reglamentada (Guereña, 2003b, p. 442).

El particular prisma a través del cual concebía la realidad el patronato describía siempre un escenario prostitucional relacionado con los bajos fondos, los grupos marginales y las zonas tradicionalmente vinculadas con el republicanismo. Del mismo modo, se intentaba confirmar la relación entre república y enfermedad sexual o entre prostitución y patología mental; no obstante, al final las causas económico-sociales ${ }^{24}$ prevalecían sobre las supuestamente congénitas y, por ello, la confirmación de esta relación resultó siempre algo forzada (Prieto, 2017, p. 3781). En el caso de la prostitución, más que por la herencia republicana, el repunte estuvo relacionado con la 


\section{Guillén Llorente-La Prostituta Como Víctima del Sistema Represivo Franquista}

carestía de aquellos años y la consiguiente situación de precariedad económica de muchas viudas o huérfanas en el difícil escenario de la posguerra. El Estado, a través de la figura del patronato adoptó entonces un rol paternalista y reeducador hacia la mujer, erigiéndose como referente principal de lo estipulado como moralmente aceptable. La prostituta y la prostitución se situaron en el centro de sus preocupaciones y sobre ellas recayó una persecución carcelaria, una legislación represiva, un discurso despectivo y una estigmatización social.

\section{Conclusiones}

Durante el franquismo se produjo un proceso de asimilación por parte del régimen de los modelos femeninos planteados por la Iglesia que dictaba el ideal de mujer: madre abnegada, esposa sumisa y devota religiosa. Sólo cuando la mujer elegía el camino familiar o religioso se encontraba bajo protección y, fuera de estos ámbitos, cualquier indicio de autonomía o libertad era interpretado como una peligrosa amenaza. Según esta lógica, el rol femenino antagonista lo personificaba la prostituta, pues en ella convergían todos los arquetipos negativos a evitar: una sexualidad sin finalidad reproductiva, una iniciativa respecto al varón y una independencia económica. Pese a que su ejercicio estuvo reglamentado durante quince años, la figura de la prostituta se vinculó, además, a problemas demográficos y de salud pública al entender que ella era causante de la disminución de la natalidad y de la trasmisión de enfermedades venéreas.

La justificación de esta actitud abiertamente contradictoria -y sin embargo coherente con el modelo dicotómico de mujer durante el franquismo- se basó en la construcción de un elaborado discurso médicopsiquiátrico que fue capaz de demostrar la necesidad del intervencionismo estatal y la reclusión de estas mujeres caídas. No obstante, es importante señalar el hecho de que el apelativo caída fue aplicado no sólo a aquéllas que ejercieron la prostitución, sino a cualquier mujer que presentase un desajuste respecto al austero patrón de comportamiento femenino diseñado por el régimen. Todas ellas serían entendidas como víctimas necesitadas de la protectora ayuda estatal y acabó imponiéndose un arbitrario sistema de vigilancia y encierro bajo la excusa de su reeducación. Fueron varias las herramientas que el régimen diseñó con esta finalidad, pero la institución del 
Patronato de Protección a la Mujer fue cardinal en tanto que sus planteamientos y objetivos incluían muchas vertientes, entre las que se encontraban tareas asistenciales, protectoras y reeducadoras. Su función, en principio preventiva, se reveló muy pronto como coercitiva y fue aplicada en dos direcciones: el intervencionismo estatal en la intimidad y la persecución y condena de la mujer desviada.

\section{Notas}

1 "Decreto por el que se organiza el Patronato de Protección a la Mujer", en Boletín Oficial del Estado, № 324, 20-XI-1941.

${ }^{2}$ En la actualidad, conocemos 14 memorias: Informe sobre la moralidad pública en España. Memoria correspondiente al año 1942. Edición reservada, destinada exclusivamente a las Autoridades, Madrid, (1942); La moralidad pública y su evolución. Memorias correspondientes al bienio 1943-1944. Edición reservada, destinada exclusivamente a las Autoridades, Patronato de Protección a la Mujer, (1944); Patronato de Protección a la Mujer: año de 1948, Ministerio de Justicia, (1948); Patronato de protección a la mujer: Memoria 19501951, Ministerio de Justicia: Gráficas Ibérica (1952); Patronato de Protección a la Mujer: Informe sobre la moralidad pública. Memoria correspondiente a los años 1942 y 1952. Patronato de Protección a la Mujer, Madrid, (1954); El Patronato de Protección a la Mujer, Ministerio de Justicia (1965, 1969, 1970,1971, 1972, 1973, 1974, 1975, 1975).

${ }^{3}$ El final oficial del patronato llegó mediante Real Decreto de 1 de agosto de 1985, siguiendo el mandato de la ley 50/1984. La última comunidad en transferir estas competencias fue Navarra en 1986, ver "Real Decreto 227/1986 de 24 de enero de traspaso de servicios de la Administración del Estado a la Comunidad Foral de Navarra en materia de protección a la Mujer", en Boletín Oficial del Estado, № 36, 11-II-1986.

4 Históricamente se advierten, al menos, tres formas de abordar la prostitución desde la perspectiva de intervención estatal: abolición, reglamentación y prohibición. El modelo prohibicionista entiende que esta actividad carece de toda legitimación legal, moral y social, siendo perseguida por el poder público con vistas a su desaparición, dada la violación de los derechos de la persona que supone, equiparando prostitución, tráfico y explotación sexual. Se considera el ejercicio de la prostitución un delito y se persigue tanto a aquellas que lo practican como a quienes lo promueven y consumen -prostitutas, clientes y proxenetas-. El abolicionismo, por su parte, castiga igualmente todas las formas de proxenetismo, pero no la prostitución en sí, pues entiende que la prostituta es víctima de una explotación sexual. Finalmente, el modelo reglamentarista consiente la existencia de locales dedicados a dicho fin y controla la actividad desde un punto de vista sanitario $\mathrm{y}$, de este modo, pretende garantizar el orden público y la salud.

5 "En esta línea de argumentación, se detecta un carácter prohibicionista en su reconocimiento de la prostitución como un medio no lícito de vida, declaración que no cabría hacerse dentro del modelo abolicionista, el cual no entiende la prostitución en sí como algo ilegal, ya que sólo 


\section{Guillén Llorente- La Prostituta Como Víctima del Sistema Represivo Franquista}

la explotación, el proxenetismo, etc., cabrían ser perseguidos por la justiciar”, en (Rivas Arjona, 2013, p. 365).

6 "En las mujeres tiene insignificante importancia el impulso interno, siendo fácil a la mujer permanecer virgen de cuerpo y de espíritu durante mucho tiempo, si las influencias externas no quebrantan la virginidad" (Vallejo Nájera, 1937, p.132).

${ }^{7}$ Principalmente Francisco Echalecu y Canino y Eduardo Martínez (Bandrés et al., 2014).

8 “... las prostitutas son a la ciudad lo que una cloaca al palacio. Suprimid esta cloaca y el palacio entero se convertirá en un lugar infecto", (San Agusín, citado por el Patronato de Protección a la Mujer, 1943, p. 215)

${ }^{9}$ Se alegó, por ejemplo, que los escritos sobre prostitución elaborados por San Agustín fueron redactados antes de recibir el bautismo, (Patronato de Protección a la Mujer, 1948, p. 53).

10 Sólo en 1941 pasaron por los dispensarios antivenéreos según los datos de la Dirección General de Sanidad, 195.997 personas afectadas por las principales enfermedades venéreas sífilis, chancro y gonorrea-y la sífilis pasó, en sólo un año, de ser la cuadragésimotercera causa dela muerte en España, a la vigésimo sexta, (Patronato de Protección a la Mujer, 1942, p. 199).

${ }^{11}$ No siempre se consiguió: en Cádiz se señala la influencia "desastrosa" de los lenocinios al situarse en "barrios honestos" y en Ourense "la mayor parte de los prostíbulos está en el mismo barrio que el Instituto de segunda enseñanza”, (Patronato de Protección a la Mujer, 1944, p. 236).

${ }^{12}$ Este sistema de encierro de mujeres desviadas no es exclusivo del franquismo, de hecho cuenta con una larga tradición en la historia de España que puede remontarse al siglo XVII con las conocidas como Casas de Galera: “...la Galera es un centro de reclusión solamente para las "malas mujeres" que, naturalmente, son muy diferentes de "otras" mujeres, las "honestas y buenas'”, (Almeda, 2005, p. 77).

13 "He ordenado la detención y encarcelamiento por treinta días de C.M.G., soltera, por dedicarse a la prostitución clandestina. Se le impone además del arresto una multa de 100 pesetas. Tan pronto como cumpla el arresto será expulsada de Murcia, no sin antes y como medida de carácter higiénico, habérsele cortado el pelo al cero" en, La Verdad, (Murcia), 19VI-1942, p. 6.

14 “...había mujeres que incluso preferían ir a prisión antes de pasar por el suplicio de los controles médicos, con un instrumental y unas condiciones higiénicas que propiciaban desgarros e infecciones", (De Miguel y Palomo, 2011, p. 324).

15 "Decreto sobre creación de prisiones especiales para regeneración y reforma de mujeres extraviadas", en, Boletín Oficial del Estado, No. 324, de 20-XI-1941.

16 Máximo Cuervo en el prólogo de La prostitución ante la moral y el derecho (Zalba, 1942, p. IX).

17 "Ley 79/1961, de 23 de diciembre, de bases para la revisión y reforma del Código Penal y otras leyes", en Boletín Oficial del Estado, No 309, de 27-XII-1961.

18 "Hay que recurrir con frecuencia a trabajos en serie, tipo standard, en los que se puede llegar a adquirir práctica sin necesidad de trabajar la inteligencia", (Patronato de Protección a la Mujer, 1965, p. 46).

19 "Para su redacción, [se refiere a los informes] la junta nacional elaboró una serie de cuestionarios que fueron remitidos a cada una de las sedes provinciales, así como a todas las jefaturas de policía de España. A partir de la respuesta de ambos organismos, la sede central 

10(2)

del patronato publicaba con cierta regularidad las memorias con información de todo tipo", (Guillén, 2018, p. 36).

${ }^{20}$ Concretamente a $5.814,558$ por ser menores de edad, a 2.306 por ejercicio clandestino, a 667 por contagio venéreo, y a 2.283 por otras causas relacionadas con la prostitución, (Patronato de Protección a la Mujer, 1942, p. 203).

${ }^{21}$ Elaboración propia a partir de los parámetros mencionados.

22 Título del ensayo de Roura, A. (2005). Un inmenso prostíbulo: mujer y moralidad durante el franquismo. Base.

23 "El ir de putas de forma ocasional o con relativa frecuencia, en solitario o en pandillas, era entonces socialmente aceptado y plenamente practicado, sea por colectivos masculinos desprovistos de pareja, los jóvenes solteros con o sin novia, los viudos o también los casados más o menos frustrados sexualmente por sus mujeres", (Guereña, 2003b, p.416-417).

24 "Del 90 al $95 \%$ de las prostitutas clandestinas pertenecen a la clase humilde. La mayor parte salieron de medios rurales para trabajar, principalmente de criadas de servir en la ciudad, y se entregaron a la prostitución al faltarles trabajo, o al quedar embarazas después de ser seducidas, (Roura 2005, p. 143).

\section{Referencias}

Almeda, E. (2005). "Pasado y presente de las cárceles femeninas en España". Sociológica, 6. http://hdl.handle.net/2183/2741

Bandrés, J., Zubieta, E., Llavona, R. (2014). "Mujeres extraviadas: psicología y prostitución en la España de posguerra". Universitas Psychologica, 13, 1667-1679.

https://doi.org/10.11144/Javeriana.upsy 13-5.mepp

De Cossío y Gómez Acebo, M. (1911). La trata de blancas en España:

ventajas de las instituciones represoras y sus resultados: Imprenta de Minuesa de los Ríos.

De Miguel, A. y Palomo, E. (2011). "Los inicios de la lucha feminista contra la prostitución: políticas de redefinición y políticas activistas en el sufragismo inglés" Brocar, 35, 315-33. https://doi.org/10.18172/brocar.1609

Escobedo, I. (2019). "Los historiadores y la prostitución balance historiográfico relativo a la etapa contemporánea". Revista Historia Autónoma, 15, 155-170. https://doi.org/10.15366/rha2019.15.008 Guereña, J. L. (2003). "El burdel como espacio de sociabilidad". Hispania, 214, 551-570. https://doi.org/10.3989/hispania.2003.v63.i214.224 
119 Guillén Llorente - La Prostituta Como Víctima del Sistema Represivo Franquista

(2003b): La prostitución en la España contemporánea. Marcial Pons.

(2012). "Prostitución y franquismo: vaivenes de una política sexual".

Guillén, C. (2018). El Patronato de Protección a la Mujer: prostitución, moralidad e intervención estatal durante el franquismo, Tesis Doctoral dirigida por Encarna Nicolás y Carmen González, Universidad de Murcia. http://hdl.handle.net/10201/64539

Lomborso, C. (1903). La donna delinquente: La prostituta e la donna normale. Bocca.

Nash, M. (1997). Recuerdos de la resistencia. La voz de las mujeres en la Guerra Civil española. Península.

Núñez, M. (2003). Mujeres caídas. Prostitución legal y clandestina en el franquismo. Oberón

Ortega, C. (2002). El fenómeno social de la prostitución femenina. Análisis socio-cultural y ético teológico, Tesis de Licenciatura, dirigida por Marciano Vidal, Universidad Pontificia Comillas de Madrid.

Osborne, R. (2009). "La sexualidad como frontera entre presas políticas y presas comunes bajo los nazis y el franquismo". Política y Sociedad, 46, 55-77.

https://revistas.ucm.es/index.php/POSO/article/view/POSO090913005 $7 \mathrm{~A}$

Prieto, L. (2017). "Control social y moralización durante el franquismo: persistencias y cambios en la valoración del comportamiento femenino", en González, D., Ortíz, M., Pérez, J. S. (Eds.). La Historia, lost in translation? Actas del XIII Congreso de la Asociación de Historia Contemporánea. Universidad de Castilla-La Mancha, 3777-3788.

(2018): Mujer, moral y franquismo: del velo al bikini, Universidad de Málaga. 
Rivas, M. (2013). "II República española y prostitución: el camino hacia la aprobación del Decreto abolicionista de 1935”. Arenal, 20, 345-368. https://revistaseug.ugr.es/index.php/arenal/article/view/1570

Roura, A. (2005). Un inmenso prostíbulo: mujer y moralidad durante el franquismo. Base.

Torres, R. (1996). La vida amorosa en tiempos de Franco. Temas de hoy Vallejo Nájera, A. (1937). Eugenesia de la hispanidad y regeneración de la raza. Ed. Española.

Zalba, M. (1942). La prostitución ante la moral y el derecho. Redención.

\section{Fuentes}

Informe sobre la moralidad pública en España. Memoria correspondiente al año 1942. Edición reservada, destinada exclusivamente a las Autoridades, Madrid, (1943)

La moralidad pública y su evolución. Memorias correspondientes al bienio 1943-1944. Edición reservada, destinada exclusivamente a las Autoridades, Patronato de Protección a la Mujer, (1944).

Patronato de Protección a la Mujer: año de 1948, Ministerio de Justicia, (1948).

Patronato de protección a la mujer: Memoria 1950-1951, Ministerio de Justicia: Gráficas Ibérica (1952).

Patronato de Protección a la Mujer: Informe sobre la moralidad pública. Memoria correspondiente a los años 1942 y 1952. Patronato de Protección a la Mujer, Madrid, (1954).

El Patronato de Protección a la Mujer, Ministerio de Justicia (1965, 1969, 1970,1971, 1972, 1973, 1974, 1975, 1975).

Carmen Guillén Llorente: Universidad de Castilla la Mancha ORCID ID: 000-0003-4727-8539

E-mail address: carmen.guillen@uclm.es 